\title{
LA DETENCIÓN DE EXTRANJEROS EN SITUACIÓN IRREGULAR: IMPACTO DE LA DIRECTIVA 2008/115/CE Y LA JURISPRUDENCIA DEL TJUE EN LA LEGISLACIÓN ESPAÑOLA DAVID FERNÁNDEZ ROJO
}

\author{
Revista de Derecho Comunitario Europeo \\ ISSN-L 1 138-4026, núm. 53, Madrid, enero/abril (2016), pp. 233-258 \\ http://dx.doi.org/10.18042/cepc/rdce.53.06 \\ Cómo citar/Citation \\ Fernández Rojo, D. (2016). La detención de extranjeros en situación irregular: \\ impacto de la Directiva 2008/1 15/CE y la jurisprudencia del TJUE en la \\ legislación española. Revista de Derecho Comunitario Europeo, 53, 233-258. \\ doi: http://dx.doi.org/10.18042/cepc/rdce.53.06
}

\section{Resumen}

La detención de extranjeros en situación irregular en centros de internamiento para garantizar su expulsión es una medida preventiva cuanto menos controvertida. El objetivo de este artículo es analizar en qué medida la legislación española, la Ley Orgánica 2/2009 y el reglamento de los centros de internamiento de extranjeros, se ajusta e incorpora efectivamente la Directiva 2008/115/CE y los numerosos pronunciamientos del Tribunal de Justicia de la Unión Europea al respecto. Concretamente, se estudian tres de los principales objetivos de la Directiva 2008/115/CE, como son establecer una política eficaz de expulsión, priorizar la concesión de un período de salida voluntaria y garantizar los derechos de los extranjeros detenidos en los centros de internamiento.

\section{Palabras clave}

Detención de extranjeros; centros de internamiento; Directiva 2008/115/CE; jurisprudencia; expulsión; salida voluntaria. 


\section{DETENTION OF IRREGULAR IMMIGRANTS: IMPACT OF THE DIRECTIVE 2008/115/EC AND THE CJEU'S DECISIONS IN THE SPANISH LEGISLATION}

\section{Abstract}

The detention of irregular immigrants in specialized centers to ensure their removal is a contentious precautionary measure. This article analyzes to what extent the Spanish legislation, both the Organic Law 2/2009 and the Royal Decree that regulates the detention facilities, effectively implement the Directive 2008/115/EC and the CJEU's decisions. Particularly, three of the main objectives of the Directive 2008/115/EC, namely establishing an effective removal policy, providing a period of voluntary departure, and guaranteeing the rights of the foreigners in detention centers are studied.

Key words

Detention of third-country nationals; detention centers; Directive 2008/115/ EC; case law, removal; voluntary departure.

\section{LA RÉTENTION D'ÉTRANGERS EN SITUATION IRRÉGULIÉRE: L'IMPACT DE LA DIRECTIVE 2008/1 15/CE ET LA JURISPRUDENCE DE LA CJUE DANS LA LÉGISLATION ESPAGNOLE}

\section{Résumé}

La rétention d'étrangers en situation irrégulière dans des centres d'internement pour garantir leur éloignement est une mesure préventive controversée. L’objet de cet article est d'analyser dans quelle mesure la législation espagnole, la Loi Organique 2/2009 et le règlement des centres d'internement d'étrangers, s'ajuste et incorpore effectivement la Directive 2008/115/CE et les nombreux prononcés du Tribunal de Justice de l'Union Européenne sur ce sujet. En particulier, ils sont étudiés trois des principaux objectifs de la Directive 2008/115/CE tels qu'établir une politique efficiente d'éloignement, donner priorité à la concession d'une période de départ volontaire et garantir les droits des étrangers retenus dans les centres d'internement.

\section{Mots clés}

Rétention d'étrangers; centres d'internement; Directive 2008/115/CE; jurisprudence; éloignement; départ volontaire. 


\section{SUMARIO}

I. INTRODUCCIÓN. II. ADOPCIÓN Y APLICACIÓN DEL MARCO LEGISLATIVO DE DETENCIÓN DE EXTRANJEROS EN ESPAÑA: UN PROCESO NO EXENTO DE AVATARES. III. INCOMPATIBILIDAD DE LA SUSTITUCIÓN DE LA SANCIÓN DE EXPULSIÓN POR LA DE MULTA CON LA DIRECTIVA 2008/115/CE: IMPLICACIONES DEL CASO ZAIZOUNE. IV. DETENCIÓN DE EXTRANJEROS EN CENTROS DE INTERNAMIENTO: LA MODESTA INFLUENCIA DE LA DIRECTIVA DE RETORNO: 1. Incoación del procedimiento de expulsión: la necesidad de conceder al extranjero en situación irregular un plazo de salida voluntaria; 2. El internamiento de extranjeros como medida excepcional; 3. Condiciones y funcionamiento de los centros de internamiento de extranjeros: el largo camino entre lo dispuesto de iure y su ejecución de facto. V. CONCLUSIÓN.

\section{INTRODUCCIÓN}

La detención de un inmigrante en situación irregular es una medida preventiva destinada a garantizar que su expulsión, devolución o regreso se lleve efectivamente a término. Los Centros de Internamiento de Extranjeros (CIE) son establecimientos no penitenciarios, donde a los extranjeros internados se les debería limitar exclusivamente su libertad deambulatoria, pues tan solo han incurrido en la infracción administrativa de encontrarse en situación irregular. Las personas detenidas pueden permanecer en los centros como máximo sesenta días, aunque de media el internamiento no sobrepasa los veintitrés días ${ }^{1}$. Actualmente están en funcionamiento siete CIE repartidos por los municipios de Algeciras, Barcelona ${ }^{2}$, Gran Canaria, Madrid, Murcia, Tenerife y Valencia. Estos centros pueden albergar un total de 2.572 internos y su funcionamiento supone al Estado anualmente un desembolso aproximado de 8,8

1 Ministerio del Interior, «Reglamento y Régimen Interior de los Centros de Internamiento de Extranjeros», 2014, disponible en http://bit.ly/1VxohZV (consultado por última vez el 11 de enero de 2016).

2 El centro de Zona Franca de Barcelona cerró provisionalmente en noviembre del año 2015 hasta que se den por concluidas, aproximadamente en marzo de 2016, las obras de renovación. 
millones de euros ${ }^{3}$. De un análisis del informe anual sobre la prevención de la tortura del Defensor del Pueblo ${ }^{4}$ y la Memoria General del Fiscal General del Estado 5 se desprende que el funcionamiento de los CIE debe ser mejorado. Asimismo, numerosas organizaciones no gubernamentales señalan que en los CIE se vulneran garantías fundamentales derivadas del mal estado de las instalaciones, la falta de equipamiento, intérpretes, traductores y la insuficiencia de los servicios sanitarios básicos, así como por las restricciones al número de visitas que pueden recibir los internos, las limitaciones para recibir asistencia letrada, la desinformación sobre su situación legal o expediente personal y al no garantizárseles su derecho a elevar quejas de forma efectiva y confidencial ${ }^{6}$.

La adopción y aplicación del marco normativo sobre la detención de extranjeros en nuestro país ha venido determinado por numerosas reformas legislativas, recursos judiciales y por la inseguridad jurídica de no contar hasta el año 2014 con un reglamento que regule específicamente el funcionamiento de los CIE. Efectivamente, la Ley Orgánica 2/2009, de 11 de diciembre, sobre derechos y libertades de los extranjeros en España y su integración social (LOEx), no solo transpuso los requerimientos mínimos sobre la detención de inmigrantes dispuestos en la Directiva 2008/115/CE (Directiva de Retorno) ${ }^{7}$, sino que a su vez otorgó un plazo de seis meses al Ejecutivo para que intro-

3 Ministerio del Interior, «Reglamento...», op. cit., nota 1.

4 Defensor del Pueblo Español, «Mecanismo nacional de prevención de la tortura: Informe Anual 2014», disponible en http://bit.ly/1mr4TC8 (consultado por última vez el 11 de enero de 2016).

5 Fiscalía General del Estado, «Memoria general Año 2015», disponible en http://bit. ly/1QD1sAU, (consultado por última vez el 11 de enero de 2016).

6 Amnistía International, «Hay alternativas: no a la detención de personas inmigrantes», 2013, disponible en http://bit.ly/1mxhvqE (consultado por última vez el $11 \mathrm{de}$ enero de 2016); Asociación Española para el Derecho Internacional de los Derechos Humanos, «Los centros de internamiento de extranjeros», 2011, disponible en http:// bit.ly/1RXJahG (consultado por última vez el 11 de enero de 2016); Consejo General de la Abogacía española, «Centros de Internamiento de Extranjeros en España: régimen vigente y propuestas de futuro", disponible en http://bit.ly/1YXloa0 (consultado por última vez el 11 de enero de 2016); Pueblos Unidos-Servicio Jesuita a Migrantes, "Situación actual de los centros de internamiento de extranjeros en España y su adecuación al marco legal vigente», 2015, disponible en http://bit.ly/1DqdrL6 (consultado por última vez el 11 de enero de 2016); Servicio Jesuita a Migrantes, «CIE y expulsiones exprés: Informe Anual 2014», 2015, disponible en http://bit.ly/1NYBAQ0 (consultado por última vez el 11 de enero de 2016).

7 Directiva 2008/115/CE del Parlamento Europeo y del Consejo, de 16 de diciembre de 2008, relativa a normas y procedimientos comunes en los Estados miembros para 
dujese una regulación de los $\mathrm{CIE}^{8}$. Pese al plazo inicialmente previsto, el Ejecutivo no sancionó hasta el 14 de marzo de 2014 el Real Decreto 162/2014 (RCIE) que regula la naturaleza, las características, la organización, las normas internas, las medidas de seguridad, la participación de las organizaciones no gubernamentales en los CIE, así como los derechos y obligaciones de los inmigrantes detenidos?.

Este trabajo analiza en qué medida la legislación española de detención de extranjeros en situación irregular incorpora efectivamente la Directiva de Retorno y los pronunciamientos al respecto del Tribunal de Justicia de la Unión Europea $(\mathrm{TJUE})^{10}$. Se entiende por extranjeros en situación irregular aquellos que bien hayan accedido a España de forma irregular (art. 25 LOEx), o bien no hayan obtenido la prórroga de estancia, carezcan de autorización de residencia o la presenten caducada por más de tres meses (art. 53.1.a LOEx). Asimismo, este trabajo no tiene por objetivo estudiar la Directiva de Retorno exhaustivamente sino tan solo aquellas disposiciones más relevantes en materia de detención, abarcándose desde la incoación del procedimiento de expulsión hasta la adopción de la medida de internamiento del extranjero ${ }^{11}$. En de-

el retorno de los nacionales de terceros países en situación irregular (DO L 348, de 24 de diciembre de 2008).

8 Ley Orgánica 2/2009, de 11 de diciembre, de reforma de la Ley Orgánica 4/2000, de 11 de enero, sobre derechos y libertades de los extranjeros en España y su integración social (BOE, núm. 299, de 12 de diciembre de 2009, p. 104986).

9 Real Decreto 162/2014, de 14 de marzo, por el que se aprueba el reglamento de funcionamiento y régimen interior de los centros de internamiento de extranjeros (BOE, núm. 64, de 15 de marzo de 2014, p. 23236).

10 A este respecto, véanse Nicholas HATZIS, «Detention of irregular migrants and the European Public Order», European Law Review, vol. 2, 2013, pp. 259-276 y Manuel LANCHA MUÑOZ, "La Directiva de Retorno a la luz de la jurisprudencia del Tribunal de Justicia de la Unión Europea", Revista de Derecho Migratorio y Extranjería, vol. 35, 2014, pp. 211-228.

11 Para un completo estudio sobre el proceso de adopción y características de la Directiva 2008/115/CE, véanse Diego ACOSTA ARCARAZO, "The good, the bad and the ugly in EU migration law: Is the European Parliament becoming bad and ugly?», European Journal of Migration and Law, vol. 11, núm. 1, 2009, pp. 19-39; Anneliese BALDACCINI, "The return and removal of irregular migrants under EU law: An analysis of the returns directive», European Journal of Migration and Law, vol. 11, núm. 1, 2009, pp. 1-17; Teresa FAJARDO DEL CASTILLO, «La Directiva sobre el retorno de los inmigrantes en situación irregular», Revista de Derecho Comunitario Europeo, vol. 13, núm. 33, 2009, pp. 453-499; Isabel REIG FABADO, «La Directiva de retorno y la tutela judicial efectiva de los extranjeros", en Libertad de circulación, asilo y refugio en la Unión Europea, Tirant lo Blanch, 2014, pp. 283-322; Karolina Miranda 
finitiva, este trabajo examina primeramente el marco normativo de detención de inmigrantes en España haciendose hincapié en los numerosos pronunciamientos judiciales y reformas legales al respecto. A continuación, se estudiará la incompatibilidad con la Directiva de Retorno, recientemente señalada por el TJUE, de la sustitución de la sanción de expulsión por la de multa para el supuesto de estancia irregular. Por último, se analizará la modesta influencia de la Directiva de Retorno y la jurisprudencia del TJUE por priorizar la concesión de un plazo de salida voluntaria y garantizar, si finalmente se recurre al internamiento, las condiciones, derechos y obligaciones de los extranjeros en los CIE.

\section{ADOPCIÓN Y APLICACIÓN DEL MARCO LEGISLATIVO DE DETENCIÓN DE EXTRANJEROS EN ESPAÑA: UN PROCESO NO EXENTO DE AVATARES}

La Ley Orgánica 7/1985 ${ }^{12}$ introdujo por primera vez la detención de inmigrantes como medida preventiva, durante un máximo de cuarenta días, mientras se tramitaba su expulsión (art. 26.2) ${ }^{13}$. Tal medida fue objeto de un recurso de inconstitucionalidad presentado por el Defensor del Pueblo, quien entendió que el internamiento de los extranjeros, al sujetarse a un procedimiento administrativo, era contrario al art. 25.3 de la Constitución española (CE) que proscribe cualquier privación de libertad por parte de la administración civil. Sin embargo, el Tribunal Constitucional (TC) concluyó que el art. 26.2 de la Ley Orgánica 7/1985 no constituye una medida administrativa sino judicial y, por tanto, constitucional ${ }^{14}$. Concretamente, el TC aclaró que la detención con el objetivo de garantizar la repatriación del inmigrante es

ZWAAN, The Returns Directive. Central themes, problem issues, and implementation in selected member states, Wolf Legal Publishers, Nijmegen, 2011.

12 Ley Orgánica 7/1985, de 1 de julio, sobre derechos y libertades de los extranjeros en España (BOE, núm. 158, de 3 de julio de 1985, p. 20824).

13 Para una visión más completa de los desarrollos normativos en la política migratoria española, véanse Rodrigo CHAVERRA AGUDELO et al., «La política de inmigración en España como instrumentalización de la alteridad», Revista Crítica Penal y Poder, vol. 9, 2015, pp. 193-216 y Blanca SÁNCHEZ ALONSO, «La política migratoria en España: Un análisis de largo plazo», Revista Internacional de Sociología, vol. 69, 2011, pp. 243-268.

14 Tribunal Constitucional (Pleno), sentencia 115/1987, de 7 de julio, FJ 1. A este respecto, véase Tribunal Constitucional, sentencias 107/1984, de 23 de noviembre, FJ 3 y 99/1985, de 30 de septiembre, FJ 2. 
constitucional siempre que concurran una serie de requisitos: a) un Tribunal de Justicia decida, teniendo en cuenta todas las circunstancias del caso, la privación de libertad del extranjero ${ }^{15}$, b) el centro de internamiento no presente carácter penitenciario, c) la detención sea una medida excepcional, y d) el extranjero tenga garantizados sus derechos fundamentales de defensa.

Si bien la detención del extranjero con el fin de llevar a término su expulsión ha sido declarada constitucional, la inseguridad jurídica de no contar con un marco regulador de tal medida judicial se mantuvo durante catorce años hasta que, el 22 de febrero de 1999, se aprobaron las reglas internas de los CIE mediante una orden ministerial ${ }^{16}$. Esta orden fue igualmente recurrida por entenderse que varias disposiciones infringían el principio constitucional de reserva de ley para regular el ejercicio de los derechos fundamentales. A este respecto, el Tribunal Supremo (TS) anuló los siguientes artículos de la Orden Ministerial que no se ajustaban al principio citado: las restricciones al derecho de visitas y comunicación con abogados y representantes consulares (art. 30.1, 2, 3, 6 y 8), la obligación de entregar al director en primer lugar las peticiones y quejas de los inmigrantes dirigidas a las organizaciones encargadas de garantizar sus derechos (art. 33.5), así como el uso de medidas coercitivas para restablecer el orden y la seguridad en el centro (art. 34.2 y 3$)^{17}$. Esta controvertida Orden se ha mantenido en vigor como principal marco regulador de los CIE en España durante aproximadamente quince años, hasta que el reciente Real Decreto 162/2014 fue aprobado.

La Orden Ministerial sobre las normas de funcionamiento y régimen interior de los CIE carecía además de una regulación detallada de los derechos y obligaciones de los inmigrantes detenidos. Por ello, la Ley Orgánica $4 / 2000^{18}$ someramente señaló que los centros debían estar equipados de servicios sociales, legales, culturales y sanitarios; aspectos que fueron de-

15 Cf. arts. 5.4 y 6.3 Convenio para la Protección de los Derechos Humanos y de las Libertades Fundamentales, hecho en Roma el 4 de noviembre de 1950, y enmendado por los Protocolos adicionales números 3 y 5, de 6 de mayo de 1963 y 20 de enero de 1966, respectivamente (BOE, núm. 243, de 10 de octubre de 1979, p. 23564).

16 Orden de 22 de febrero de 1999 sobre normas de funcionamiento y régimen interior de los centros de internamiento de extranjeros (BOE, núm. 47, de 24 de febrero de 1999, p. 7681).

17 Tribunal Supremo (Sala de lo Contencioso-Administrativo), sentencia 3009/2005, de 11 de mayo.

18 Ley Orgánica 4/2000, de 11 de enero, sobre derechos y libertades de los extranjeros en España y su integración social (BOE, núm. 10, de 12/01/2000). 
sarrollados mediante el Real Decreto 864/2001 ${ }^{19}$. Empero, el TS anuló el art. 130.2 y 6 de dicho Real Decreto, relativo a las medidas aplicables a los internos que no respetasen las normas de los centros y las limitaciones a las comunicaciones de los inmigrantes detenidos respectivamente, por introducir medidas restrictivas insuficientemente específicas de derechos fundamentales no previstas en la Ley Orgánica $4 / 2000^{20}$. Este pronunciamiento del TS puso de relieve la necesidad de regular mediante ley orgánica los derechos, obligaciones, la información a facilitar a los inmigrantes detenidos, su derecho a formular peticiones y quejas, así como las medidas de seguridad interna y funcionamiento de los CIE. Tales disposiciones fueron incorporadas en la Ley Orgánica 14/2003 ${ }^{21}$, enmendada a su vez por el TC que declaró el art. 58.5 y 6 inconstitucional ${ }^{22}$.

Finalmente, la Ley Orgánica 2/2009 sobre derechos y libertades de los extranjeros en España y su integración social es la última reforma adoptada en materia de extranjería. Esta nueva ley se aprobó, como indica el preámbulo, con el objetivo de incluir y armonizar los numerosos desarrollos legislativos y jurisprudenciales antes descritos, transponer la normativa comunitaria en política de migración y asilo, así como adaptar la normativa nacional a los nuevos retos planteados por el fenómeno migratorio. Asimismo, la disposición adicional tercera de la Ley Orgánica 2/2009 otorgó un plazo de seis meses al Gobierno para que aprobara un reglamento sobre el régimen de detención de extranjeros. Sin embargo, no fue hasta el 14 de marzo de 2014 cuando se aprobó el Real Decreto 162/2014 sobre el funcionamiento y régimen interior de los $\mathrm{CIE}^{23}$. Este reglamento regula e introduce algunas mejoras en el régimen de internamiento e infraestructuras, así como en la regulación de los

19 Real Decreto 864/2001, de 20 de julio, por el que se aprueba el Reglamento de ejecución de la Ley Orgánica 4/2000, de 11 de enero, sobre derechos y libertades de los extranjeros en España y su integración social, reformada por Ley Orgánica 8/2000, de 22 de diciembre (BOE, núm. 174, de 21 de julio de 2001, p. 26552).

20 Tribunal Supremo (Sala de lo Contencioso-Administrativo), sentencia 1924/2003, de 20 de marzo.

21 Ley Orgánica 14/2003, de 20 de noviembre, de Reforma de la Ley Orgánica 4/2000, de 11 de enero, sobre derechos y libertades de los extranjeros en España y su integración social (BOE, núm. 279, de 21 de noviembre de 2003, p. 41193).

22 Tribunal Constitucional, sentencia 17/2013, de 31 de enero.

23 Para un análisis más completo del nuevo RCIE, véase Alberto DAUNIS RODRÍGUEZ, «Reglamento de los centros de internamiento de extranjeros: una nueva oportunidad perdida», Diario La Ley, núm. 8418, 2014; Mariano LÓPEZ BENÍTEZ «El nuevo régimen jurídico de los Centros de Internamiento de Extranjeros», Revista Vasca de Administración Pública, vol. 99-100, 2014, pp. 1905-1935. 
servicios sociales, médicos, asistenciales, recreativos y jurídicos de los centros donde se detienen a los extranjeros.

A pesar de la breve historia del RCIE, cuatro de sus artículos (arts. 7.3 párrafo $1^{\circ}, 16.2$ párrafo $\mathrm{k}, 21.3$ y 55.2, párrafo $2^{\circ}$ ) han sido anulados por el TS el 10 de febrero de $2015^{24}$. Además, el Defensor del Pueblo y varias organizaciones no gubernamentales consideran que varias disposiciones del RCIE no están siendo aún efectivamente puestas en práctica por el Ejecutivo ${ }^{25}$. Precisamente, los siguientes apartados de este artículo analizan en qué medida la Ley Orgánica 2/2009 y el RCIE incorporan y se ajustan adecuadamente a la normativa y jurisprudencia comunitaria sobre la detención de extranjeros ${ }^{26}$.

\section{INCOMPATIBILIDAD DE LA SUSTITUCIÓN DE LA SANCIÓN DE EXPULSIÓN POR LA DE MULTA CON LA DIRECTIVA 2008/115/CE: IMPLICACIONES DEL CASO ZAIZOUNE}

Tan pronto como la policía comprueba que un extranjero está en situación irregular en España se prepara su expediente sancionador de expulsión. Su detención en un CIE tiene como objetivo garantizar, como medida administrativa preventiva, el cumplimiento de su repatriación. La estancia irregular de los extranjeros no es el único supuesto de internamiento previsto en la Ley de Extranjería ${ }^{27}$. Se contempla también la detención para llevar a término la devolución (art. 58.3 LOEx), el regreso (art. 60.1 LOEx) o la expulsión como medida sustitutiva de la pena de prisión (art. 89 del Código Penal). Ahora bien, tan solo la estancia irregular en territorio español, si no concurre ningún otro agravante, conlleva una infracción administrativa sancionable mediante multa en vez de expulsión. Esta sustitución ha sido considerada incompatible con la Directiva 2008/115/CE por la sentencia del TJUE de 23 de abril de 2015 (caso

24 Tribunal Supremo (Sala de lo Contencioso-Administrativo), sentencia 373/2014, de 10 de febrero de 2015. Véase, Margarita YANINI MIŃARRO, «Los Centros de Internamiento de Extranjeros y Política Inmigratoria: ¿Orden público o cuestión social?», Estudios Financieros, núm. 386, 2015, pp. 162-167.

25 Véanse las notas 4 y 6.

26 Especial mención se hará a la Recomendación de la Comisión Europea, «que establece un 'Manual de Retorno' común destinado a ser utilizado por las autoridades competentes de los Estados miembros en las tareas relacionadas con el retorno», COM(2015) 6250 final, 1.10.2015.

27 Art. 62.1 LOEx en relación al art. 53.1 apdos. a, d y f, art. 54.1 apdos. a y b, y art. 57.2 LOEx. 
Zaizoune $)^{28}$. Por ello, en este apartado se analizan las implicaciones que este reciente pronunciamiento presenta para la normativa nacional de detención.

$\mathrm{El}$ art. 55.1.b LOEx establece que la estancia irregular de los extranjeros es sancionable mediante multa, no obstante, esta puede ser sustituida por la expulsión del territorio español conforme el principio de proporcionalidad (art. 57.1 LOEx). El TS ha aclarado que la expulsión, al ser una medida más restrictiva que la multa, precisa de razones específicas y complementarias para ser aplicada. Solo en aquellos casos en los que, además de la permanencia irregular en España, concurran en el expediente administrativo del inmigrante datos negativos de suficiente entidad sobre su conducta, procedería imponer la sanción de expulsión ${ }^{29}$. Sin embargo, tan pronto como la Directiva de Retorno entró en vigor, el TS en su sentencia de 12 de marzo de 2013 estableció que aquella «obligará a modular la interpretación hasta ahora efectuada, y la aplicación de las normas legales que permiten en ciertos supuestos elegir entre la expulsión y la multa de los extranjeros en situación irregular» ${ }^{30}$. Efectivamente, el sistema de multa y expulsión español ha sido declarado incompatible con la Directiva de Retorno en el caso Zaizoune.

El TJUE, en dos pronunciamientos anteriores al caso Zaizoune, sostuvo justamente lo contrario, que el derecho comunitario no se oponía a la sanción de multa en el supuesto de estancia irregular. Concretamente, en la sentencia de 22 de octubre de 2009, el TJUE se pronunció sobre el sistema español de multa y expulsión apuntando que «[...] al margen de si la multa se paga o no, dicha resolución se notifica al interesado con la advertencia de que debe abandonar el territorio en un plazo de quince días, y que, si no obedece [...] podrá ser expulsado de forma inmediata " ${ }^{31}$. A este respecto, el TJUE concluyó que el marco normativo facultativo para los Estados en ese momento ${ }^{32}$ era

28 Sentencia del Tribunal de Justicia Zaizoune (C-38/14, EU:C:2015:260).

Véanse, entre otras, Tribunal Supremo (Sala de lo Contencioso-Administrativo), sentencias 8138/2005, de 22 de diciembre; 280/2006, de 31 de enero; 528/2006, de 10 de febrero; 2332/2006, de 21 de abril; 5642/2006, de 29 de septiembre; 1230/2007, de 22 de febrero y 2379/2008, de 27 de mayo.

30 Tribunal Supremo (Sala de lo Contencioso-Administrativo), sentencia 988/2013, de 12 de marzo, FJ 7.

31 Sentencia del Tribunal de Justicia Zurita García y Choque Cabrera (C-261/08 y C-348/08, EU:C:2009:648), apartado 65.

32 Arts. 6 ter y 23 del Convenio de aplicación del Acuerdo Schengen, de 14 de junio de 1985 y art. 11.3 del Reglamento (CE) núm. 562/2006 del Parlamento Europeo y del Consejo, de 15 de marzo de 2006, por el que se establece un Código comunitario de normas para el cruce de personas por las fronteras (Código de fronteras Schengen), (DO L 105, de 12 de abril de 2006, p. 1). 
compatible con la no adopción de una resolución de expulsión al extranjero residente irregular ${ }^{33}$. Por otro lado, el 6 de diciembre de 2012, el TJUE se pronunció sobre si la Directiva 2008/115/CE es compatible con una normativa de un Estado miembro que sanciona la residencia irregular con una pena de multa sustituible por una pena de expulsión o de arresto domiciliario. El TJUE entendió que «una pena pecuniaria no impide de modo alguno que se adopte y se ejecute una decisión de retorno con pleno cumplimiento de los requisitos enunciados en $[\ldots]$ la Directiva $[\ldots] »^{34}$.

Sin embargo, en el reciente caso Zaizoune se concluyó que «la Directiva 2008/115/CE [...] debe interpretarse en el sentido de que se opone a la normativa de un Estado miembro [...] que [...] impone, dependiendo de las circunstancias, o bien una sanción de multa, o bien la expulsión, siendo ambas medidas excluyentes entre sí». El TJUE entiende que la normativa española, pese a ser más favorable, puede demorar el retorno de los extranjeros en situación irregular y poner en riesgo el efecto útil de la Directiva ${ }^{35}$. El principal objetivo de la Directiva es la introducción de un régimen de expulsión y retorno efectivo ${ }^{36}$, por lo que los Estados miembros, cuando se encuentran frente a un extranjero en situación irregular, pueden bien ordenar la expulsión del extranjero que habrá de llevarse a término, o bien concederle el estatus de residente ${ }^{37}$.

33 Sentencia del Tribunal de Justicia Zurita García y Choque Cabrera (C-261/08 y C-348/08, EU:C:2009:648), apdo. 66. Véase José Luis RODRÍGUEZ CANDELA y Manuel LANCHA MUÑOZ, "Multa vs. expulsión en el derecho de extranjería español frente a la estancia irregular, antes y después de la directiva de retorno", SEPIN, septiembre 2015, disponible en http://bit.ly/1JFgwtL (consultado por última vez el 11 de enero de 2016).

$$
\text { dos. }
$$
dos. 33 y 39 y El Dridi (C-61/11, EU:C:2011:268), apdo. 59. Para un análisis en profundidad del caso El Dridi, véanse Alessia DI PASCALE y Bruno NASCIMBENE, «La Sentencia del Tribunal de Justicia el DRIDI y la inmigración irregular. Problemas y perspectivas en el Derecho de la Unión Europea y en el Derecho Italiano", Revista Española de Derecho Europeo, vol. 42, 2012, pp. 107-128; Leonardo PASQUALI, «iLa pena de prisión para inmigrantes irregulares perjudica la política de retorno de la Unión?», Revista de Derecho Comunitario Europeo, 2011, vol. 15, núm. 39, pp. 541-558 y Rosa RAFFAELLI, «Criminalizing Irregular Immigration and the Returns Directive: An Analysis of the El Dridi Case», European Journal of Migration and Law, vol. 13, núm. 4, 2011, pp. 467-489.

37 Diego ACOSTA ARCARAZO y Andrew GEDDES, «The Development, Application and Implications of an EU Rule of Law in the Area of Migration Policy», Journal of Common Market Studies, vol. 51, núm. 2, 2013, p. 186. 
Especialmente disputada es la interpretación del art. 24 RD 557/2011, de 20 de abril, por el que se aprueba el Reglamento de Extranjería, que el propio TJUE menciona pero sin entrar a analizar en el caso Zaizoune. El referido artículo expone que la sanción de multa viene acompañada tanto por un requerimiento legal e imperativo de abandono del territorio español en el plazo de quince días prorrogables, así como por la advertencia de sanción de expulsión en caso de incumplimiento de tal obligación. De tal manera que si el extranjero no abandona el país en el plazo voluntario de quince días habrá de ser requerido de nuevo por la administración y se le incoará entonces un procedimiento preferente sancionador de expulsión acompañado de la medida preventiva de internamiento en un CIE para garantizar su repatriación. Por tanto, tiene razón el TJUE cuando estima que el sistema nacional es contrario al propósito de la Directiva de llevar a cabo de forma efectiva el retorno del extranjero, pues tan pronto como la medida de multa ha sido incumplida y aquel no ha abandonado el país en quince días, se retrasa de forma indefinida (hasta que el extranjero sea de nuevo requerido por la policía) o se impide definitivamente su repatriación ${ }^{38}$.

No comparte la anterior interpretación del art. 24 RD 557/2011 la Subcomisión de Extranjería del Consejo General de la Abogacía Española en su circular del 25 de mayo de $2015^{39}$ al considerar que la sanción de multa viene necesariamente sucedida por la medida de expulsión. A este respecto, entiende que el apercibimiento de salida obligatoria en el plazo máximo de quince días que acompaña a la sanción de multa constituye un plazo de salida voluntaria en la que no se puede, conforme a los arts. 6.1 y 8.2 de la Directiva, hacer cumplir efectivamente la expulsión. Si en el plazo de quince días el extranjero en situación irregular no abandona voluntariamente el país, se adoptará separadamente, como permite el art. 8.3 de la Directiva, un acto administrativo de expulsión preferente garantizándose el retorno del extranjero mediante su internamiento en un CIE. En definitiva, viene a concluir que la sanción de multa y expulsión no son excluyentes entre sí, sino que la multa procura un período de salida voluntario que si se incumple conlleva sucesiva y necesariamente la apertura de un procedimiento de expulsión. Estima, por tanto, el Consejo General de la Abogacía Española que las cuestiones prejudiciales

38 Pablo GONZÁLEZ SAQUERO, «La regulación de la expulsión administrativa por estancia irregular en España, incompatible con la Directiva 'retorno' (Sentencia del Tribunal de Justicia, asunto C-38/14, Zaizoune)», Revista Española de Derecho Europeo, vol. 55, 2015, pp. 133-158.

39

Subcomisión de extranjería del Consejo General de la Abogacía Española, Circular 43/2015, argumentario a la Sentencia de 23 abril 2015 del TJUE, 27.5.2015. 
que se plantearon al TJUE no fueron claras y que no han sido comprendidas adecuadamente por el Tribunal. No obstante, debe aclararse que la sanción de multa no viene sucedida necesariamente por la medida de expulsión como pretende hacer entender el Consejo General de la Abogacía Española, sino que realmente entre estos dos procedimientos separados pueden transcurrir años si el extranjero, cuando le es impuesta la multa, no abandona en quince días el país. Por ello, el sistema de multa y expulsión conculca uno de los principales objetivos de la Directiva de Retorno, como es llevar a término de forma efectiva la repatriación del extranjero.

De lo que no cabe duda es que la reciente sentencia del TJUE es vinculante e impide la imposición de la sanción de multa a los extranjeros que se encuentren en situación irregular. A este respecto, si bien algunos tribunales ya han comenzado a aplicar la sentencia del TJUE a casos iniciados antes del 23 de abril de $2015^{40}$, la jurisprudencia será más abundante con posterioridad ${ }^{41}$. Dado que de ahora en adelante los tribunales españoles han de adoptar necesariamente una resolución de expulsión, estos están prestando acertadamente especial atención al hecho de que se garantice un período voluntario de salida durante el cual no se puede internar al extranjero en un $\mathrm{CIE}^{42}$. La concesión de un período de salida voluntario es uno de los principales objetivos de la Directiva de Retorno y únicamente puede verse restringido caso por caso cuando exista un riesgo cierto que impida la expulsión efectiva del extranjero ${ }^{43}$.

40 TSJ de la Región de Murcia, Sala de lo Contencioso-administrativo, Sección 1a, Sentencia 927/2015 de 30 de octubre de 2015, Rec. 234/2015; TSJ de Valladolid, Sala de lo Contencioso-administrativo, Sentencia 2386/2015 de 23 de octubre de 2015, Rec. 402/2015; TSJ Castilla y León (Sala de lo Contencioso-Administrativo, Sección 3a), sentencia 2676/2015, de 20 de noviembre; TSJ Madrid (Sala de lo Contencioso-Administrativo), sentencia 680/2015, de 29 octubre; TSJ Andalucía, Sevilla (Sala de lo Contencioso-Administrativo, Sección $3^{\text {a }}$ ), sentencia 880/2015, de 8 de octubre; TSJ País Vasco (Sala de lo Contencioso-Administrativo, Sección 2a), sentencia 433/2015, de 29 de septiembre.

41 Como señala el Consejo General de la Abogacía en su Circular 43/2015, sería procedente acogerse a la doctrina implantada por el Tribunal Europeo de Derechos Humanos en Del Río Prada v. Spain [GC], núm. 42750/09, ECHR-II donde se estableció que no es posible aplicar retroactivamente en el ámbito sancionador los cambios interpretativos originados en la jurisprudencia.

42 TSJ de Murcia, Sala de lo Contencioso Administrativo, Sección 2a, Sentencia 819/2015, de 25 de noviembre, FJ 2. Véase también, TSJ de Murcia, Sala de lo Contencioso-Administrativo, Sección 2a, Sentencia 887/2015, de 30 de noviembre.

Manual de Retorno, op. cit., nota 26, p. 37. 


\section{DETENCIÓN DE EXTRANJEROS EN CENTROS DE INTERNAMIENTO: LA MODESTA INFLUENCIA DE LA DIRECTIVA DE RETORNO}

La Directiva 2008/115/CE tiene entre sus objetivos establecer una política efectiva de retorno, contemplándose para ello la posibilidad de que los Estados miembros internen a los extranjeros objeto de un procedimiento de expulsión para que no eviten o dificulten dicho proceso. Ahora bien, la detención de un inmigrante en situación irregular ha de venir estricta, necesaria y proporcionalmente delimitada, pues supone una grave intrusión en su derecho fundamental a la libertad. Este apartado analiza específicamente la modesta influencia que la Directiva de Retorno y su desarrollo jurisprudencial presentan de cara a priorizar la concesión de un plazo de salida voluntaria, limitar la detención de extranjeros y garantizar sus derechos en los centros de internamiento nacionales.

\section{INCOACIÓN DEL PROCEDIMIENTO DE EXPULSIÓN: LA NECESIDAD DE CONCEDER AL EXTRANJERO EN SITUACIÓN IRREGULAR UN PLAZO DE SALIDA VOLUNTARIA}

Tan pronto como la policía verifica que un extranjero está en situación irregular se inicia su expediente sancionador que con anterioridad podía ser de expulsión o de multa. Dada la incompatibilidad de la sanción de multa con la Directiva de Retorno, dictada por el TJUE en el caso Zaizoune, a los inmigrantes en situación irregular se les abrirá de ahora en adelante un expediente de expulsión que podrá tramitarse mediante el procedimiento ordinario o preferente. El procedimiento general a seguir será el ordinario, el preferente solo es aplicable cuando el extranjero suponga un riesgo para el orden público, la seguridad pública o la seguridad nacional, haya riesgo de incomparecencia, así como en el caso de que evitara o dificultase su expulsión (art. 63.1 LOEx) ${ }^{44}$. La aplicación de un procedimiento u otro no es cuestión baladí, dado que ciertas garantías y derechos de los extranjeros pueden verse ampliamente limitados.

44 El art. 63.1.b LOEx señala que cuando los extranjeros eviten o dificulten su expulsión será de aplicación el procedimiento preferente y no se otorgará un plazo voluntario de salida. La anterior excepción no viene específicamente estipulada por el art. 7.4 de la Directiva de Retorno. No obstante, dada la indeterminación de la excepción del art. 63.1.b LOEx, esta podría subsumirse en el concepto «riesgo de incomparecencia» del art. 63.1.a LOEx, la cual sí viene recogida como excepción en la Directiva de Retorno. 
En el procedimiento ordinario el plazo para presentar alegaciones es de quince días (art. 228.1 RD 557/2011), en el preferente se ve reducido a cuarenta y ocho horas (art. 63.4 LOEx), pero proporcionándosele al extranjero asistencia letrada de oficio (art. 63.3 LOEx). Asimismo, el procedimiento ordinario, pero no así el preferente, otorga al extranjero un plazo de cumplimiento voluntario entre siete y treinta días para que abandone el territorio nacional (art. 63bis.2 LOEx). A este respecto, el extranjero que se encuentra en situación irregular y abandona el territorio nacional durante el plazo de salida voluntario previsto en el procedimiento ordinario verá revocada la prohibición de entrada que se le haya impuesto junto con el expediente de expulsión. De lo contrario, si su expulsión se tramita mediante el procedimiento preferente la prohibición de entrada se aplicará salvo que el inmigrante abandone el país mientras se formaliza su expediente administrativo sancionador (art. 58.2 LOEx ${ }^{45}$. Por último, el procedimiento preferente permite, entre otras medidas preventivas, adoptar el internamiento del extranjero en un CIE (art. 63.2 LOEx); medida que está expresamente prohibida en el procedimiento ordinario (63bis.3 LOEx).

La concesión de un plazo voluntario de salida del país, previsto en el procedimiento ordinario, conforma uno de los objetivos fundamentales de la Directiva de Retorno por constituir una medida más digna, segura y eficiente que la expulsión acompañada del internamiento preventivo en un centro ${ }^{46}$. Tan solo se podrá denegar el período de salida voluntaria cuando concurran las circunstancias excepcionales mencionadas en el art. 7.4 de la Directiva de Retorno ${ }^{47}$. A falta de datos oficiales por parte del Ministerio del Interior, Eurostat estima que en 2014 fueron retornadas (objeto de devolución y expulsión) de nuestro país 15.150 personas, de las cuales tan solo 2.855 salieron de forma voluntaria ${ }^{48}$. Este dato refleja que en España sigue conservando más peso el procedimiento preferente que no otorga un plazo voluntario de salida.

45 El art. 245.2 RD 557/2011 establece que la salida del territorio deberá ser oportunamente comunicada bien a los servicios policiales responsables del control fronterizo, o bien mediante personación en la misión diplomática u oficina consular española en el país de origen o de residencia del inmigrante. Manual de Retorno, op. cit., nota 26, p. 37.

47 Sentencia del Tribunal de Justicia El Dridi (EU:C:2011:268), apdo. 37.

48 Eurostat, «Third-country nationals who have left the territory by type of return and citizenship», 6 de octubre de 2015. Estos datos pueden no ser del todo exactos pues los Estados miembros no tienen obligación de facilitar estadísticas diferenciando las expulsiones de los retornos que se han producido acogiéndose al período de salida voluntaria. Cf. Communication from the Commission to the Council and the European Parliament on EU Return Policy, COM(2014) 199 final, 28 de marzo de 2014. 
Ello se debe en parte a que, hasta el reciente caso Zaizoune, el procedimiento preferente se tramitaba directamente si el extranjero en situación irregular había sido sancionado previamente con una multa y no había salido en el plazo voluntario de quince días que concede el art. $24 \mathrm{RD} 557 / 2011^{49}$.

La Directiva de Retorno ha influido de forma modesta pero positivamente en la legislación española respecto a la concesión de un plazo voluntario de salida. Concretamente, la Ley Orgánica 2/2009 introdujo por primera vez el art. 63 bis donde se estipula que el procedimiento ordinario, que incluye dicho plazo, es el generalmente aplicable ${ }^{50}$. Sin embargo, la legislación española no se ajusta adecuadamente a las exhaustivas y estrictas ${ }^{51}$ excepciones del art. 7.4 de la Directiva 115/2008/CE que permiten a los Estados miembros «abstenerse de conceder un plazo para la salida voluntaria, o [...] conceder un período inferior a siete días".

El incumplimiento de las medidas impuestas por razón de seguridad pública (art. 53.1.d LOEx), la participación por el extranjero en actividades contrarias al orden público (art. 53.1.f LOEx), la seguridad nacional (art. 54.1.a LOEx) y la facilitación de la inmigración clandestina (art. 54.1.b LOEx) se ajustan a la excepción del art. 7.4 de la Directiva de Retorno relativa al riesgo que puede representar el extranjero para el orden público, la seguridad pública o la seguridad nacional. Sin embargo, cuando la Ley de Extranjería señala que se aplicará el procedimiento preferente siempre que el extranjero tenga antecedentes penales (art. 57.2 LOEx), asumiéndose de forma generalizada que estas personas suponen un riesgo para el orden y la seguridad pública, no puede incardinarse en la excepción del art. 7.4 de la Directiva. Precisamente, en el asunto $Z$ h. y $O$., el TJUE expuso que los Estados miembros están obligados a apreciar el concepto de riesgo para el orden público caso por caso, valorándose de forma individualizada la gravedad del acto, el tiempo que hace desde que este se cometió, así como cualquier otro elemento fáctico determinante ${ }^{52}$. El TJUE concluyó que el hecho de que un extranjero «haya sido condenado penalmente [...] no basta, por sí solo, para justificar que se considere que dicho nacional representa un riesgo para el orden público en el sentido del art. 7 , apartado 4, de la Directiva 2008/115 ${ }^{53}$. En definitiva, el art. 63.1 LOEx, que

49 Circular 1/2010, de 25 de enero, de la Dirección General de la Policía y de la Guardia Civil, instrucciones sobre determinadas actuaciones policiales derivadas de la nueva ley 2/2009, de 11 de diciembre, que modifica la Ley Orgánica 4/2000, de 11 de enero, de extranjería y recordatorio de otras actuaciones.

50 José Luis RODRÍGUEZ CANDELA, op. cit., nota 33.

51 Sentencia del Tribunal de Justicia, Zh. y O. (C-554/13, EU:C:2015:377), apdo. 50.

52 Ibíd., apdo. 65.

53 Ibíd., apdo. 50. 
niega un plazo voluntario de salida del país al concebir que todos los extranjeros con antecedentes penales suponen un riesgo para el orden o la seguridad pública, ha de entenderse contrario al art. 7.4 de la Directiva de Retorno como recientemente ha interpretado el TJUE.

Por último, el art. 63.1 LOEx deniega la concesión de un período de salida voluntaria a los extranjeros que se encuentren en situación irregular si existe riesgo de incomparecencia. El riesgo de incomparecencia ha venido delimitado por la circular 1/2010 de la Comisaría General de Extranjería y Fronteras pese a que el art. 3 de la Directiva de Retorno apunta a que dicho riesgo ha de venir definido por ley ${ }^{54}$. Esta circular fija los criterios a seguir por la policía para decantarse por el procedimiento preferente: el extranjero carece de domicilio fijo y estable, no presenta documentación, exhibe documentación caducada, fue anteriormente sancionado o incumplió una salida obligatoria. La Directiva no equipara, como hace la legislación española, la incomparecencia con la denegación del plazo voluntario de salida, sino que prioriza la concesión de este a través del empleo de las medidas preventivas establecidas en el art. 7.3 de la Directiva de Retorno ${ }^{55}$. A este respecto, el TJUE, caso Ali Mahdi, ha declarado que cualquier apreciación sobre el riesgo de incomparecencia deberá basarse en un examen individual del caso y en criterios objetivos ${ }^{56}$. El riesgo de incomparecencia ha de tener en cuenta todas las circunstancias personales del extranjero, lo que en ocasiones puede determinar que el mero hecho de, por ejemplo, no contar con documentación no pueda suponer la denegación del período voluntario de salida ${ }^{57}$.

\section{EL INTERNAMIENTO DE EXTRANJEROS COMO MEDIDA EXCEPCIONAL}

La Directiva de Retorno establece que el internamiento de un extranjero en un centro se llevará a cabo siempre y cuando no puedan aplicarse con eficacia otras medidas suficientes de carácter menos restrictivo (art. 15.1).

54 José Luis RODRÍGUEZ CANDELA, op. cit., nota 33.

55 Conclusiones de la abogado general Sharpston en el asunto Zh. y O. (C-554/13, EU:C:2015:377), punto 39. Cf. José Luis RODRÍGUEZ CANDELA, op. cit., nota 33.

56 Sentencia del Tribunal de Justicia Ali Mahdi, EU:C:2014:1320. Véase también Sentencia del Tribunal de Justicia Sagor (EU:C:2012:777), apartado 41. No obstante, el criterio para determinar el riesgo de fuga por parte del TJUE es bastante vago, dejándole al juez nacional una amplia libertad interpretativa, cf. Marie-Laure BASILIEN-GAINCHE, "Immigration Detention under the Retum Directive: The CJEU Shadowed Lights», European Journal of Migration and Law, vol. 17, 2015, p. 112.

57 Manual de Retorno, op. cit., nota 26, pp. 11-12. 
El TJUE, dictaminó en El Dridi que «los Estados miembros deben llevar a cabo la expulsión a través de las medidas menos coercitivas posibles ${ }^{58}$ y que la privación de libertad debe ser el último recurso. Las medidas para llevar a término la expulsión han de graduarse desde la menos severa, como es la concesión de un plazo de retorno voluntario, hasta las más restrictivas, como es el internamiento en un $\mathrm{CIE}^{59}$. El art. 61.1 LOEx también regula la detención de extranjeros como una medida excepcional, pues limita la libertad del inmigrante. A este respecto, y tras la aprobación del RCIE, se emitió por la Dirección General de la Policía la circular 6/2014 que dicta los criterios para solicitar al juez instructor la medida preventiva de internamiento de los extranjeros ${ }^{60}$. Se han de considerar las circunstancias personales del extranjero, su arraigo en España o en su país de origen, la posibilidad real de que la persona sea efectivamente expulsada, se debe consultar a ACNUR la eventualidad de repatriar al inmigrante y si ello conllevaría un riesgo para su vida o integridad física, así como valorar cualquier otra medida menos gravosa para la libertad del extranjero.

Sin embargo, en la práctica la detención de inmigrantes en un CIE es una medida recurrente y cuasiautomática previa expulsión del interesado de nuestro país. Si bien el objetivo de la detención es asegurar una repatriación del extranjero, en 2014 hubo 7.340 extranjeros internados en los CIE y tan solo 3.483 fueron efectivamente expulsados. Un $52 \%$ de los internados no han sido repatriados, un alto porcentaje que deja entrever que se emplea de forma excesiva y poco efectiva la gravosa medida de detención en un CIE. Se incumple por tanto no solo uno de los principales objetivos de la Directiva de Retorno, como es garantizar una expulsión efectiva de los extranjeros en situación irregular ${ }^{61}$, sino también la introducción y aplicación de medidas alternativas a la detención. La evaluación de la Directiva 2008/115/CE, publicada el 22 de octubre de 2013, destaca que en España se prevén medidas alternativas a la detención, pero la falta de información disponible sobre su aplicación práctica, salvo en el supuesto de la retirada del pasaporte, denota su falta de uso ${ }^{62}$.

58 Sentencia del Tribunal de Justicia El Dridi (C-61/11, EU:C:2011:268), apdo. 39.

59 Ibíd., apdo. 41.

60 Circular 6/2014, de 11 de julio, de la Dirección General de la Policía, criterios para solicitar el ingreso de ciudadanos extranjeros en los centros de internamiento.

61 Sentencia del Tribunal de Justicia El Dridi (C-61/11, EU:C:2011:268), apdo. 59.

62 European Commission (DG Home Affairs), "Evaluation on the application of the Return Directive (2008/115/EC)», 22 de octubre de 2013, pp. 29-34, disponible en http://bit.ly/1ME9B6J (consultado por última vez el 11 de enero de 2016). Existen varios estudios y artículos que abordan medidas alternativas al internamiento en un 
Tabla 1. Relación de extranjeros detenidos en un CIE y expulsiones llevadas a cabo en España

\begin{tabular}{|l|r|r|r|r|r|}
\hline & $\begin{array}{c}\text { Detenciones } \\
\text { propuestas } \\
\text { por Fiscalía }\end{array}$ & $\begin{array}{c}\text { Detenciones } \\
\text { acordadas } \\
\text { por los } \\
\text { juzgados }\end{array}$ & $\begin{array}{c}\text { Inmigrantes } \\
\text { expulsados }\end{array}$ & $\begin{array}{c}\text { Inmigrantes } \\
\text { no } \\
\text { expulsados }\end{array}$ & $\begin{array}{r}\text { Porcentaje de } \\
\text { expulsiones }\end{array}$ \\
\hline 2014 & 6.761 & 7.340 & 3.483 & 3.857 & 47,45 \\
\hline 2013 & 6.988 & 9.002 & 4.726 & 4.276 & 52,49 \\
\hline 2012 & 8.807 & 11.325 & 5.924 & 5.401 & 52,30 \\
\hline 2011 & 10.272 & 11.456 & 6.825 & 4.631 & 59,57 \\
\hline
\end{tabular}

FUENTE: Defensor del Pueblo Español, «Mecanismo nacional de prevención de la tortura: Informe Anual 2014», y Fiscalía General del Estado, «Memoria general año 2015».

Además, dada la excepcionalidad de la medida preventiva de detención, la Directiva de Retorno establece que la duración del internamiento del extranjero ha de ser lo más corta posible siempre con el fin de garantizar la efectiva salida del extranjero del país. No obstante, el límite temporal instaurado por la normativa comunitaria es bastante amplio: seis meses, prorrogables durante doce meses más si se produce una falta de cooperación por el internado o se retrasa la obtención de la documentación necesaria para tramitar la expulsión (art. 15.5). Si bien la legislación española es en este aspecto más

CIE en España, véanse Teresa DÍAZ OLTRA, «Hay alternativas: no a la detención de personas inmigrantes», en Isabel REIG FABADO, Libertad de circulación, asilo y refugio en la Unión Europea, Tirant Lo Blanch, 2014, pp. 417-422; Carmelo FALEH PÉREZ, «El encierro de extranjeros en España: crítica y alternativas a los CIE desde el sistema universal de protección de los derechos humanos», Revista Electrónica Iberoamericana, vol. 7, núm. 2, 2013, pp. 99-117 y José Miguel SÁNCHEZ TOMÁS, "Hacia un sistema alternativo al internamiento de inmigrantes irregulares», Eunomía. Revista en Cultura de la Legalidad, vol. 5, 2014, pp. 75-94. Así como numerosos estudios a nivel europeo, véase Philippe DE BRUYCKER (ed.), «Alternatives to Immigration and Asylum Detention in the EU», 2015, disponible en http://bit.ly/1JX4hMm, (consultado por última vez el 11 de enero de 2016); European Migration Network, "The use of detention and alternatives to detention in the context of immigration policies», 2014, disponible en http://bit.ly/22FXLIQ (consultado por última vez el 11 de enero de 2016); International Detention Coalition, There are Alternatives, 2015, disponible en http://bit.ly/1Nf2EdD (consultado por última vez el 11 de enero de 2016); Robyn SAMPSON y Mitchell GRANT, «Global Trends in Immigration Detention and Alternatives to Detention: Practical, Political and Symbolic Rationales", Journal on Migration and Human Security, vol. 1, núm. 3, 2013, pp. 97-121. 
garantista, la Ley Orgánica 2/2009 extendió el plazo anterior de cuarenta días a los actuales sesenta (art. 62(2) LOEx y art. 21 RCIES) ${ }^{63}$. Por otro lado, el TJUE ha dictaminado que el internamiento ha de concluir tan pronto como no haya perspectivas razonables de que la expulsión se llevará a término, que el plazo máximo de detención se haya alcanzado o que otras medidas preventivas menos gravosas resulten más apropiadas ${ }^{64}$. A este respecto, el TJUE en el caso $K a d z o e v^{65}$ dispuso que tan pronto como se alcance «la duración máxima del internamiento prevista [...] la persona interesada debe ser inmediatamente puesta en libertad [...]» ${ }^{66}$. Finalmente, la Directiva de Retorno contempla la detención de un mismo extranjero tras haber sido internado previamente si ha sobrevenido un significativo cambio en las circunstancias que llevaron a la primera detención ${ }^{67}$. De igual forma se pronunció el TS al permitir que se soliciten nuevas detenciones por causas diferentes, pero anuló el art. 21.3 RCIES que establecía «un nuevo internamiento del extranjero, por las mismas causas que determinaron el internamiento anterior, cuando habiendo ingresado

63 European Commission (DG Home Affairs), op. cit., nota 62, pp. 44-50.

64 Sentencia del Tribunal de Justicia Mahdi (EU:C:2014:1320), apartado 64.

65 Este caso es muy relevante respecto a la detención de inmigrantes para un análisis más exhaustivo, véanse Galina CORNELISSE, «Case C-357/09 PPU, Proceedings Concerning Said Shamilovich Kadzoev (Huchbarov), Judgment of the European Court of Justice (Grand Chamber) of 30 November 2009", Common Market Law Review, vol. 48, núm. 3, 2011, pp. 925-945 y Pablo GONZÁLEZ SAQUERO, «El internamiento de extranjeros y sus límites. Sentencia del TJUE as. Kadzoev (2009)», Administración y justicia: un análisis jurisprudencial: liber amicorum Tomás-Ramón Fernández, 2012, pp. 3305-3326.

66 Sentencia del Tribunal de Justicia, Kadzoev (C-357/09, EU:C:2009:74), apdos. 60, 67 y 71 . Un aspecto muy controvertido es el limbo jurídico en el que se quedan aquellos extranjeros en situación irregular que no pueden ser expulsados y a los que tampoco se les ofrece un permiso de residencia, vid. Diego ACOSTA ARCARAZO, «The Charter, detention and possible regularization of migrants in an irregular situation under the Returns Directive: Mahdi», Common Market Law Review, vol. 52, núm. 5, 2015, pp. 1361-1378; Marie-Laure BASILIEN-GAINCHE, op. cit., nota 56, pp. 122 y ss.; European Commission, "Study on the situation of third-country nationals pending return/removal in the EU Member States and the Schengen Associated Countries», 2013, disponible en http://bit.ly/1TF3fah (consultado por última vez el 11 de enero de 2016); Adriana MORÁN JARRÍN, «La construcción de la persona inmigrante en el limbo jurídico: ni expulsables ni regularizables en España», Cadernos de Campo, vol. 21, núm. 21, pp. 301-318 y Maaike VANDERBRUGGEN, et al., «Point of no return: the futile detention of unreturnable migrants», 2014, disponible en http://bit.ly/1mgVJ6p (consultado por última vez el 11 de enero de 2016).

67 Manual de Retorno, op. cit., nota 26, p. 98. 
con anterioridad no hubiera cumplido el plazo máximo de sesenta días, por el período que resta hasta cumplir este» ${ }^{68}$.

Por último, la Directiva de Retorno establece que dadas las graves consecuencias para la libertad que conlleva la detención del extranjero, esta ha de ser ordenada por escrito y por autoridades administrativas o judiciales (art. 15.2). En el caso Madhi se señala que la autoridad judicial debe realizar un estudio completo de los hechos del caso, incluyendo las observaciones que haga el extranjero interesado. Particularmente, el derecho a ser oído del internado es un derecho fundamental que ha de venir garantizado por los Estados miembros tal y como apunta el TJUE en los asuntos Mukarubega y Boudjlida ${ }^{69}$. El juez asimismo ha de valorar en todo momento «la posibilidad de ordenar una medida alternativa o la puesta en libertad del nacional del país tercero» ${ }^{70}$. La Ley de Extranjería española prevé que toda detención de un inmigrante en situación irregular se ordenará (juez de instrucción) y controlará (juez de control) por la autoridad judicial en todo momento (art. 60.3 LOEx y art. 2 RCIES ${ }^{71}$. El juez de control, creado por la Ley Orgánica 2/2009 y radicado allí donde se encuentre el CIE, se encarga de supervisar la estancia de los extranjeros, recibir sus quejas, garantizar sus derechos fundamentales, visitar los centros y autorizar el uso de la fuerza o el aislamiento previamente acordado por el director del CIE (art. $57 \mathrm{RCIE})^{72}$. Si bien los jueces de control han interpretado de forma amplia su mandato y garantizan un mejor respeto de los derechos de los inmigrantes detenidos, sus poderes y tareas deberían haber sido precisadas en la Ley Orgánica 2/2009 y el RCIE ${ }^{73}$.

68 Tribunal Supremo (sala de lo contencioso administrativo), sentencia 373/2014, de 10 de febrero de 2015, FJ 5 (las cursivas son nuestras).

69 Sentencia del Tribunal de Justicia Mukarubega (C-166/13, EU:C:2014:2336) y Boudjlida (C-249/13, EU:C:2014:2431). Sin embargo, la sentencia del Tribunal de Justicia G. y R. (C-383/13, EU:C:2013:533) ha precisado que el derecho a ser oído no es absoluto y puede "ser objeto de restricciones" (apartado 33, en relación con apartado 44). Cf. Marie-Laure BASILIEN-GAINCHE, op. cit., nota 56, pp. 119122.

70 Sentencia del Tribunal de Justicia Mahdi (EU:C:2014:1320), apartado 62.

71 European Commission (DG Home Affairs), op. cit., nota 62, pp. 35-43.

72 Para un análisis en profundidad de las resoluciones de los jueces de control, véase Cristina MANZANEDO, "Resoluciones de los juzgados de control de los centros de internamiento de extranjeros (CIE) 2009-2013", Revista de Derecho Migratorio y Extranjeria, vol. 34, 2013, pp. 249-259.

73 Alberto DAUNIS RODRÍGUEZ, op. cit., nota 23, p. 8. 


\section{CONDICIONES Y FUNCIONAMIENTO DE LOS CENTROS DE INTERNAMIENTO DE EXTRANJEROS: EL LARGO CAMINO ENTRE LO DISPUESTO DE IURE Y SU EJECUCIÓN DE FACTO}

La Directiva de Retorno establece que los centros de internamiento no deben tener naturaleza penitenciaria ${ }^{74}$, no obstante, si un Estado miembro no puede detener a los extranjeros en un centro especializado y se ve obligado a recurrir a un establecimiento carcelario, aquellos deberán permanecer siempre separados de los presos (art. 16.1) ${ }^{75}$. La Ley Orgánica 2/2009 prohíbe específica y taxativamente el internamiento de un extranjero en un centro penal. A este respecto, los arts. 60.2 LOEx y 1.2 RCIE decretan que los CIE han de venir necesariamente equipados con servicios sociales, legales, culturales y médicos, pues el único derecho que se limita a los extranjeros internados es su libertad deambulatoria. Ahora bien, los CIE en la práctica siguen presentando un carácter, si no carcelario, eminentemente policial ${ }^{76}$. En primer lugar, según el art. 3 RCIE, el Ministerio del Interior, concretamente la Dirección General de la Policía, está a cargo de dirigir, coordinar e inspeccionar los centros. Asimismo, los agentes de policía pueden portar sus armas (art. 11.4 RCIE), un extremo confirmado por el TS que puntualizó, no obstante, que sería más adecuado no llevarlas en un centro de carácter no penitenciario ${ }^{77}$. En segundo lugar, los arts. 53 a 57 regulan las medidas de seguridad que pueden adoptarse en los CIE. El TS anuló el art. 55.2 RCIE que permitía en situaciones excepcionales realizar registros personales de los internos, incluyéndose el desnudo integral, para garantizar la seguridad del centro o si había motivos racionalmente fundados para creer que el interno escondía objetos o sustancias prohibidas $^{78}$. El TS concluyó que tal artículo no era razonable o proporcionado, pues interfería con los derechos fundamentales de privacidad y dignidad del inmigrante, a quien exclusivamente se le puede privar de su libertad

74 Sentencia del Tribunal de Justicia Bero y Bouzalmate (C-473/13 y C-514/13, EU:C:2014:2095), apartado 32.

75 Sentencia del Tribunal de Justicia Thi Ly Pham (EU:C:2014:2096, apartado 21) y Conclusiones del abogado general Yves Bot en el asunto Thi Ly Pham (EU:C:2014:2096), punto 100 .

76 Cristina MANZANEDO y Daniel IZUZQUIZA, «Expulsiones forzosas de España: los centros de internamiento de extranjeros (CIE)», Miedo, inseguridad y control social, vol. 161, 2011, p. 160.

77 Tribunal Supremo (Sala de lo Contencioso Administrativo), sentencia 373/2014, de 10 de febrero de 2015, FJ 4.

78 Ibíd., FJ 7. Cf. Manual de Retorno, op. cit., nota 26, p. 90. 
deambulatoria ${ }^{79}$. Por último, el TS consideró ajustado a derecho y conforme con los arts. 16.1 y 18.1 de la Directiva de Retorno el art. 5.2 RCIES que autoriza al Ejecutivo, en situación de emergencia, siempre que los centros existentes estén desbordados, la creación de centros temporales de internamiento no carcelarios ${ }^{80}$.

La Directiva de Retorno asimismo establece en su art. 16 las principales condiciones y derechos de los inmigrantes internados en los CIE. El punto decimoséptimo del preámbulo señala que a los extranjeros internados se les ha de garantizar un «trato digno y humano que respete sus derechos fundamentales y se ajuste al Derecho internacional y nacional». Dado que la Directiva no entra a regular de forma exhaustiva tales derechos, el art. 16 ha de entenderse complementado $\operatorname{por}^{81}: 1$ ) las veinte directrices sobre el retorno forzoso del Consejo de Europa, concretamente la décima sobre las condiciones de la detención antes de la expulsión ${ }^{82}$; 2) las normas del Comité Europeo para la Prevención de la Tortura y de las Penas o Tratos Inhumanos o Degradantes ${ }^{83}$; 3) la recomendación del Comité de Ministros a los Estados miembros sobre las Reglas Penitenciarias Europeas ${ }^{84}$; 4) las reglas mínimas de la ONU para el tratamiento de los reclusos ${ }^{85}$.

79 Tribunal Constitucional (Pleno), sentencia 17/2013, de 31 de enero, FJ 14, dictaminó que las medidas de aislamiento, el uso de la fuerza física y las inspecciones son excepcionales y para que puedan considerarse constitucionales deben cumplir dos requisitos: tener como objetivo garantizar la seguridad y el orden del centro, así como constituir una respuesta proporcionada al comportamiento del extranjero. El TS, refiriéndose a esta STC, anuló la disposición del RCIE que permitía el desnudo integral al extranjero por considerar que era una medida desproporcionada de cara a comprobar si el individuo estaba escondiendo objetos o sustancias prohibidas.

80 Tribunal Supremo (Sala de lo Contencioso Administrativo), sentencia 373/2014, de 10 de febrero de 2015, FJ 3.

81 Manual de Retorno, op. cit., nota 26, p. 104.

82 Consejo de Europa, Guidelines on forced return, septiembre 2005, disponible en http://bit.ly/22yHyly (consultado por última vez el 11 de enero de 2016).

83 Consejo de Europa, Normas del Comité Europeo para la Prevención de la Tortura y de las Penas o Tratos Inhumanos o Degradantes, 2002, disponible en http://bit. ly/22yHVt1 (consultado por última vez el 11 de enero de 2016).

84 Consejo de Europa, Recomendación del Comité de Ministros a los Estados miembros sobre las Reglas Penitenciarias Europeas (adoptada por el Comité de Ministros el 11 de enero de 2006, a raíz de la 952 reunión de delegados de ministros), Rec(2006)2ES, disponible en http://bit.ly/1OsUJ9R (consultado por última vez el 11 de enero de 2016).

85 Primer Congreso de las Naciones Unidas sobre Prevención del Delito y Tratamiento del Delincuente, Reglas mínimas para el tratamiento de los reclusos, celebrado en Ginebra en 1955, y aprobadas por el Consejo Económico y Social en sus resolucio- 
Si bien el RCIE regula los derechos, obligaciones y el funcionamiento de los CIE de forma detallada, en la práctica no se están viendo efectivamente implementados ${ }^{86}$, lo que contraviene el art. 16 de la Directiva. A este respecto y a modo ejemplificativo, las zonas de ocio no han sido creadas, el personal sanitario es insuficiente, los inmigrantes internados no tienen acceso a internet o teléfonos móviles, su derecho a presentar quejas ante el juez de control no está garantizado y los servicios culturales y sociales no han sido introducidos $^{87}$. De igual manera se ha pronunciado el Defensor del Pueblo español y la Fiscalía General del Estado. Aquel, tras ocho visitas a los CIE en 2014, expuso que varios artículos del RCIE no han sido efectivamente implementados y propuso varias recomendaciones al respecto ${ }^{88}$. La Fiscalía General del Estado, una vez efectuadas nueve visitas a los CIE durante 2014, enfatizó las pobres condiciones de los centros, la insuficiencia de sus servicios médicos y sociales disponibles, así como la falta de medios de comunicación y asistencia lega ${ }^{89}$. Por último, las organizaciones no gubernamentales y asociaciones encargadas de proteger los derechos de los inmigrantes han subrayado que el nuevo RCIE prácticamente no ha supuesto ninguna mejoría en las condiciones de los inmigrantes internos ${ }^{90}$. El Ministerio del Interior, sorpresivamente, el 23 de septiembre de 2015, admitió que algunos preceptos del RCIE no se estaban aplicando dadas las restricciones presupuestarias y el numeroso personal necesario para ponerlos en práctica ${ }^{91}$. Extremo que ya viene previsto en el propio RCIE, en su disposición adicional segunda, donde se establece que

nes 663C (XXIV) de 31 de julio de 1957 y 2076 (LXII) de 13 de mayo de 1977, disponible en http://bit.ly/1P0ew0Z (consultado por última vez el 11 de enero de 2016).

86 A este respecto, véase Carmen AZCÁRRAGA MONZONÍS, "Centros de Internamiento de Extranjeros. Principales denuncias y novedades legislativas», Barataria, Revista Castellano-Manchega de Ciencias Sociales, vol. 17, 2014, pp. 143-163; Rosana GARCIANDÍA GARMENDIA, «Los centros de internamiento de extranjeros en España a examen", Anuario Español de Derecho Internacional, vol. 27, 2015, pp. 467-492; Adriana JARRÍN MORÁN, Dan RODRÍGUEZ GARCÍA y Javier DE LUCAS, «Los Centros de Internamiento para Extranjeros en España: una evaluación crítica», Revista CIDOB d'Afers Internacionals, vol. 99, 2012, pp. 201-220.

87 Juez de control a cargo del CIE en Barranco Seco (Las Palmas), 31 de julio de 2015.

88 Defensor del Pueblo Español, op. cit., nota 4, pp. 63-71 y 150-152.

89 Fiscalía General del Estado, op. cit., nota 5, pp. 440-443.

90 Véase nota 6.

91 El País, «Interior reconoce que incumple la legalidad en los Centros de Extranjeros», 19 de octubre de 2015, disponible en http://bit.ly/1NQX9Vf (consultado por última vez el 11.1.2016). 
«la aplicación de este reglamento no conllevará incremento del gasto público ni supondrá incremento de dotaciones, de retribuciones, o de otros gastos de personal al servicio del sector público».

\section{CONCLUSIÓN}

Si bien la Directiva de Retorno no constituye una panacea al controvertido asunto de la detención de inmigrantes ${ }^{92}$, ni tampoco el TJUE ha destacado por su concreción y claridad en la materia ${ }^{93}$, tanto la normativa como la jurisprudencia comunitaria han tenido un impacto en la Ley Orgánica 2/2009 y en el reciente Reglamento de los centros de internamiento de extranjeros. A este respecto, el TJUE, en el caso Zaizoune, ha declarado incompatible con la Directiva de Retorno la medida nacional más favorable de sustitución de la sanción de expulsión por la de multa en el supuesto de extranjeros en situación irregular.

Mientras que el legislador español no actúe, y en ausencia de un nuevo pronunciamiento del TJUE en vía prejudicial, son los tribunales españoles los que han de incorporar obligatoriamente la nueva doctrina europea. Anteriormente, la sanción de multa, acompañada de un período voluntario de salida del país de quince días, se aplicaba al supuesto de estancia irregular, siempre y cuando no concurrieran, en relación con la conducta del extranjero, otros datos negativos de suficiente entidad. De esta manera, si la multa no se abonaba o la salida del territorio nacional no se producía, se tramitaba, mediante el procedimiento preferente, su expulsión tan pronto como fuera nuevamente identificado por las autoridades. Sin embargo, de ahora en adelante habrá de aplicarse con carácter general el procedimiento ordinario que concede al extranjero, a diferencia del procedimiento preferente, un plazo de salida voluntario. Por tanto, la transposición excesivamente amplia que realiza la legislación española de las excepciones de la Directiva de Retorno en lo que respecta a la concesión de un plazo de salida voluntaria del extranjero, exige una interpretación restrictiva por parte de los tribunales nacionales; de lo contrario, es de esperar que el TJUE declare la transposición de la Directiva en España, en aquellos extremos que resulten no conformes, incompatible con el Derecho de la Unión.

92 Anneliese BALDACCINI, op. cit., nota 10, pp. 1-17; Diego ACOSTA ARCARAZO, "The good...», op. cit., nota 10, pp. 19-39.

93 Marie-Laure BASILIEN-GAINCHE, op. cit. nota 56, pp. 104-126. 
Por otro lado, la Directiva de Retorno establece como objetivo fundamental que el recurso a la medida preventiva de internamiento del extranjero en situación irregular conlleve efectivamente su expulsión. Las autoridades españolas, sin embargo, abusan de la medida de internamiento de los extranjeros en los CIE ya que, de las 7.340 personas detenidas en 2014, tan solo 3.483 fueron finalmente expulsadas; ello supone que haya habido 3.857 internamientos que no cumplieron el objetivo de llevar a término efectivamente la repatriación. No obstante, hay que tener presente que la Directiva de Retorno, en previsión de las dilaciones derivadas de la obtención de la documentación necesaria de terceros países (art. 15.6.b), y de las dificultades que pudieran surgir a la hora de llevar efectivamente a cabo la expulsión cuando el extranjero en situación irregular evita, dificulta o no coopera a tal fin (arts. 15.1.b y 15.6.a), otorga un plazo máximo de dieciocho meses de detención en un centro, mientras que en nuestro país, por el contrario, las autoridades cuentan con un plazo mucho más abreviado y garantista (sesenta días) para efectuar la repatriación del inmigrante irregular. Ante tal disyuntiva, con vistas a hacer compatible el texto de la Directiva con la práctica nacional, la solución pasa por que los tribunales de justicia nacionales pongan en práctica las medidas alternativas a la detención previstas en el art. 235.6 RD 557/2011 ${ }^{94}$, como son la retirada del pasaporte, la presentación periódica ante las autoridades competentes, la residencia obligatoria en determinado lugar o cualquier otra medida que el juez estime necesaria.

94 Véase nota 62. 